\title{
Mapping of Quantitative Trait Loci (QTLs) Associated with Sugarcane Aphids Resistance in Recombinant Inbreed Population of Sorghum [Sorghum bicolor (L.) Moench]
}

\author{
S.P. Mehtre ${ }^{1 *}$, C.T. Hash ${ }^{2}$, H.C. Sharma ${ }^{2}$, S.P. Deshpande ${ }^{2}$ and G.W. Narkhede , $^{\text {** }}$ \\ ${ }^{1}$ Vasantrao Naik Marathwada Krishi Vidyapeeth, Parbhani 431402 (MS) India \\ ${ }^{2}$ International Crops Research Institute for the Semi-Arid Tropics (ICRISAT), \\ Patancheru, 502324, Telangana India
}

*Corresponding author

\section{A B S T R A C T}

\section{Keywords}

Sorghum, Aphid

Resistance,

Quantitative Trial

Loci (QTL)

Article Info

Accepted:

26 February 2019

Available Online:

10 March 2019
Mapping of QTL associated with sorghum aphid resistance was undertaken in a recombinant inbred population derived from 296B (susceptible) x IS 18551 (Resistance) parents. Totally 2 QTLs spread across linkage group were detected at threshold LOD of 2.50. The alleles of IS 18551 contributed to increase aphid tolerance. QTL analysis across season revealed that QTL mapped on LG ' $\mathrm{J}$ ' was a major one, explaining $20.4 \%$ of the observed phenotypic variance with a peak LOD value 9.2 and showed nonsignificant Q $x$ E interaction. This major QTL flanked by two linked markers i.e. Xtxp 15 - Xtxp 283 and it will be targeted for marker-assisted selection in a practical breeding program aiming at increasing the level of resistance in agronomically elite backgrounds through gene pyramiding for aphid resistance.

\section{Introduction}

Sorghum is the fifth most important cereal crop globally after rice, maize, wheat, and barley. It is grown in about 86 countries covering an area about 47 million hectares (ha) with a grain production of 69 million ton and average productivity of $1.96 \mathrm{t} / \mathrm{ha}$ (ICRISAT, 1996; FAO, 2004). India is a major producer of sorghum with the crop occupying an area of 9.9 million ha and yielding an annual production of 8.0 million ton during 2003-04 (FAS, 2005). The productivity of sorghum is highly variable from country to country. Several constraints affect grain productivity. Among these drought and pests are the predominant ones.

Sugarcane aphid (Melanaphis sacchari) prefers to feed on the under the surface of older leaves. The damage proceeds from the lower to upper leaves. The nymph and adults suck sap from the lower surface of leaves, and this leads to stunted plant growth. The damage is more serve in crops under drought stress and results in drying up of leaves and plant mortality. The insects' population increases rapidly at the end of the rainy season during 
dry spells. Its infestation is high during the post-rainy season in India and aphid infestation spoils the crop fodder quality (Waghmare et al., 1995).

In addition to the temperature, cloudy weather together with increasing humidity can result in aphid colonies completely covering the abaxial surface of all leaves of sorghum plants (Mote 1983). Aphid density was greater under irrigation than in rainfed conditions and its occurrence on sorghum at milk stage, deteriorated fodder quality (Balikai, 2001). Sorghum grain and fodder yield losses ranging from minor to severe have been reported in India (Mote and Kadam, 1984; Mote et al., 1985). In Sorghum, the losses varied between $12-26$ and $10-31 \%$ with an overall loss of 16 $\%$ and $15 \%$ for grain and fodder yield, respectively (Balikai, 2001).

The selection of sorghum genotypes for resistance to aphids by utilizing one or few resistance parameters is inefficient because several components are involved in resistance and one or more genes govern each of these resistance components.

Further, expression of many of these components is influenced by environmental variation; hence aphid resistance is a quantitative trait and shows a large amount of genotype x environmental interaction. Markerassisted selection has considerable potential to improve the efficiency of selection for quantitative traits (Hash and Bamel Cox, 2000).

In the present investigation we tried to map aphid resistance QTLs, the ultimate goal of such QTL analysis is to develop tools that are useful for marker-assisted selection in a practical breeding programme aiming at increasing the level of resistance in the agronomically elite background through gene pyramiding for aphid resistance.

\section{Materials and Methods}

The experiment consisted of a set of 213 recombinant inbred lines (RILs) ( $\mathrm{F}_{7: 8}$ ) derived from a cross between two sorghum inbred lines viz. 296B (susceptible to aphid) and IS 18551 (tolerance to aphid). The RIL population progenies along with both parents were used for phenotyping and genotyping.

The RILs were produced at ICRISAT, Patancheru. After the initial cross between 296B and IS 18551, a single $F_{1}$ plant was selfed. The resulting $\mathrm{F}_{2}$ seeds were sown and $\mathrm{F}_{2}$ plants were selfed. The $\mathrm{F}_{3}$ seeds were sown head-to-row, each $\mathrm{F}_{3}$ plant was selfed and from each head-to-row, a single plant was randomly chosen to provide the seeds for the next generation, and this was repeated for 3 to 4 generations, up to $F_{7}$. The bulk seed was harvested from randomly selected $\mathrm{F}_{6}$ plants to produce $213 \quad \mathrm{~F}_{7}$ recombinant inbred lines (RILs).

\section{Evaluation of RILs for resistance to Aphids}

Screening of the RIL for Aphid resistance was carried out at ICRISAT, Patancheru. A total of 254 lines (213 RILs +14 times repeated check of each of 296B and IS 18551 and a standard check, CSH 9 repeated 13 times), were sown on $16^{\text {th }}$ August, during the 2002 kharif season (E1). For early rabi season (E2), a total of 224 entries (213 RILs + 4 times repeated checks of each of 296B and IS18551) + standard check CSH 9 repeated 3 times were sown on $16^{\text {th }}$ October 2004. The test material was planted in balanced alpha design with $75 \mathrm{~cm}$ and $10 \mathrm{~cm}$ inter and intra row spacing respectively. In the late kharif and rabi seasons, each entry was grown in two-row plots of $2 \mathrm{~m}$ length in four and three replications respectively. Aphid damage was evaluated at crop maturity on 1 to 9 scale, where $1=$ aphid present with no apparent damage to the leaves and $9=$ heavy aphid density on infested leaves. 
Genotyping 213 RILs of 296B x IS 18551 mapping populations using 114 SSR markers The genetic linkage map has been constructed using map marker / exp 3.0 with the LOD threshold value at 3.0 and linkage distance (cm units) calculated using the Haldane (1919) mapping function. Markers were mapped in 10 linkage groups with a total map length of $2165.8 \mathrm{~cm}$.

\section{QTL analysis}

A total number of 213 RIL progenies from the cross 296B x IS 18551 were used for markertrait associations. The BLUPS of these 213 RILS were used for QTL analyses. QTL analyses were performed by using composite interval mapping (CIM) (Jansen and Stam 1994; Zeng 1994). Required computations were performed using Plab QTL version 1.1 (Utz and Melchinger 2000), which performs CIM by employing interval mapping using a regression approach (Haley and Knott, 1992) with selected markers as cofactors. The presence of a putative QTL, in an interval, was tested using the Bonferroni X2 approximation (Zeng 1994) corresponding to a genome-wise type I error of 0.25 . Since the mapping population used in the present study was constituted of RILs, the additive model 'AA' was employed for analyses in which additive $\mathrm{x}$ additive epistatic effects were included. The point at which the LOD score had the maximum value in the interval was taken as the estimated QTL position. QTLs detected in different environments were treated as common if their estimated position were within $20 \mathrm{~cm}$ of each other and their estimated effects had an identical sign. QTL $x$ environments interaction was analyzed over all three environments as described by Utz and Melchinger (2000). The proportion of genetic variance explained by the QTL was adjusted for QTL x environment interactions to avoid overestimation. After the QTL analysis with Plab QTL, the QTLs identified for components of resistance were assigned to the linkage group based on linkage position of markers on the linkage map developed by Bhattramakki et al., (2000).

\section{Results and Discussion}

The phenotypic data from two screening environments and genotypic data for 213 RILs were subjected to QTL analysis. The results of this RIL analysis for aphid resistance presented (Table 1, Fig. 1). Two aphid resistance QTLs were detected based on phenotypic evaluation in the kharif screening environment and one QTL was detected based on rabi screening environment. One of the QTLs detected mapped on the same position of LG 'J' (Linkage group J), for both screening environment and one QTL mapped to $L G$ ' $E$ ' based on kharif (E1) screening.

The two QTLs together explained 31.5\% of the observed phenotypic variance for this trait in kharif screening. Final simultaneous analysis revealed that $22.7 \%$ of the adjusted phenotypic variance was explained by these two QTLs which had combined peak LOD score of $12.7 \%$. The single QTL detected in Rabi screening explained $10.4 \%$ of the observed phenotypic variance, the final simultaneous fit analysis revealed that only $6 \%$ of the adjusted phenotypic variance was explained by this single QTL with a peak LOD score of 3.26. A favorable additive genetic effect for low aphid incidence was contributed by alleles from aphid tolerant parent IS 18551 in both screening environments. A major QTL for aphid resistance was mapped on LG ' $J$ ' in the marker interval Xtxp15 - Xtxp283.

QTL analysis across season revealed that two aphid resistance QTLs were detected in the across seasons. These mapped on LG ' $E$ ' and LG 'J'. 
Table.1 Characteristics of QTLs associated with aphid resistance in two screening environments Kharif, Rabi and across seasons based on composite interval mapping (PLAB QTL, LOD 2.5) using RIL population derived from 296B x IS 18551

\begin{tabular}{|c|c|c|c|c|c|c|c|c|}
\hline Environment / Trait & $\begin{array}{l}\text { Linkage } \\
\text { group }\end{array}$ & Position & Marker Interval & $\begin{array}{c}\text { Superior } \\
\text { Interval }(\mathbf{c m})\end{array}$ & Peak LOD & $\mathbf{R}^{2}$ & $\begin{array}{c}\text { Effect } \\
\text { (Additive) }\end{array}$ & $\begin{array}{c}\mathbf{G} \times \mathbf{E} \\
\text { interaction }\end{array}$ \\
\hline \multirow{4}{*}{$\begin{array}{l}\text { Aphid damage score } \\
\text { Kharif, Patancheru (E1) }\end{array}$} & $\mathrm{E}$ & 34 & Xtxp40 - Xtxp159 & $22-46$ & 6.94 & 14.3 & -0.392 & -- \\
\hline & $\mathrm{J}$ & 150 & Xtxp15 - Xtxp283 & $140-160$ & 7.70 & 17.2 & -0.349 & -- \\
\hline & \multicolumn{5}{|c|}{ Sum: 2 QTLs } & 31.5 & & \\
\hline & \multicolumn{4}{|c|}{ Final Simultaneous fit } & $\mathrm{LOD}=12.73$ & \multicolumn{3}{|c|}{ Adj. $R^{2}=22.7 \%$} \\
\hline \multirow[t]{3}{*}{ Rabi Patancheru (E2) } & $\mathrm{J}$ & 144 & Xtxp15-Xtxp283 & $132-156$ & 4.47 & 10.4 & -0.229 & -- \\
\hline & \multicolumn{5}{|c|}{ Sum: 1 QTL } & 10.4 & & \\
\hline & \multicolumn{4}{|c|}{ Final Simultaneous fit } & $\mathrm{LOD}=3.26$ & \multicolumn{3}{|c|}{ Adj. $R^{2}=6.0 \%$} \\
\hline \multirow[t]{4}{*}{ Across season (Averages) } & $\mathrm{E}$ & 40 & Xtxp40-Xtxp159 & $18-64$ & 2.58 & 5.5 & -0.191 & $* *$ \\
\hline & $\mathbf{J}$ & 148 & Xtxp15-Xtxp283 & $138-156$ & 9.26 & 20.4 & -0.312 & NS \\
\hline & \multicolumn{5}{|c|}{ Sum: 2 QTLs } & 25.9 & & \\
\hline & \multicolumn{4}{|c|}{ Final Simultaneous fit } & $\mathrm{LOD}=10.35$ & \multicolumn{3}{|c|}{ Adj. $R^{2}=18.6 \%$} \\
\hline
\end{tabular}


Figure.1 QTL position of sugar cane aphid resistance for 213 recombinant inbred populations derived from cross $296 \mathrm{~B} \times$ IS 18551 across two screening environments at Patancheru, during 2002-2004

A

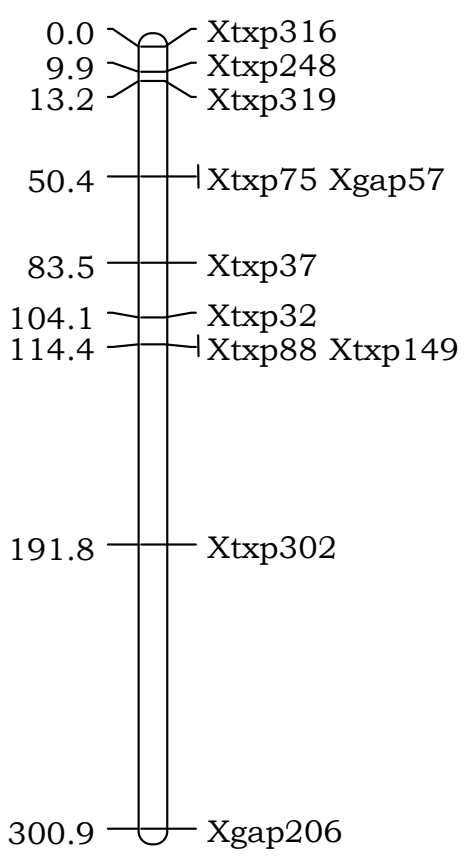

B

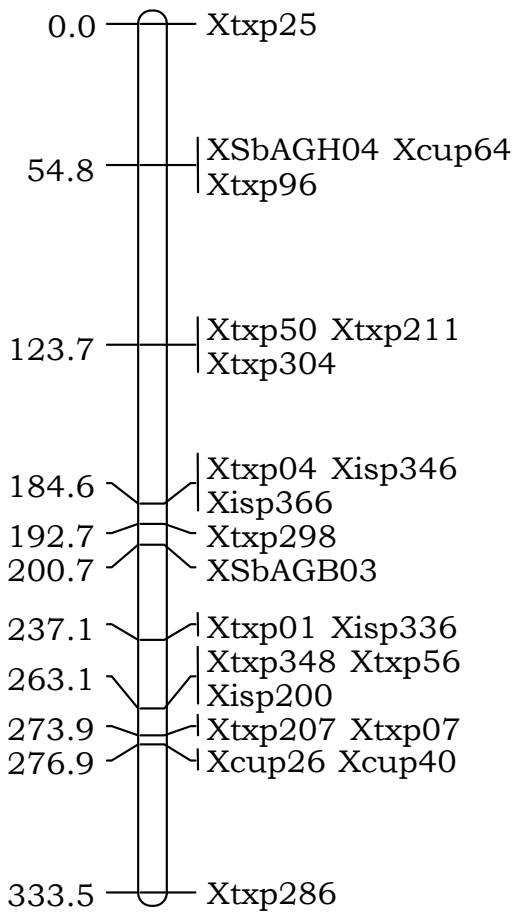

C

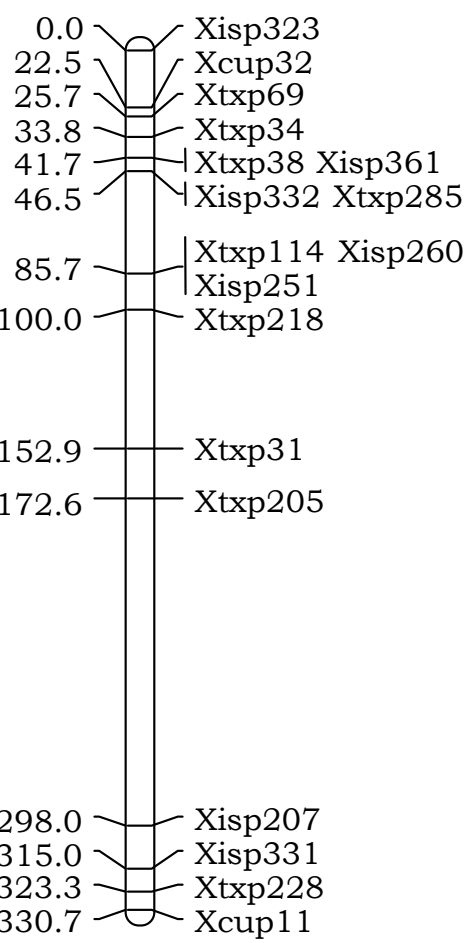

D-

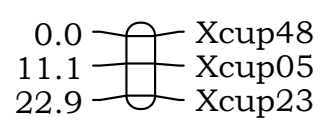

11.17 Xcup05

(1)

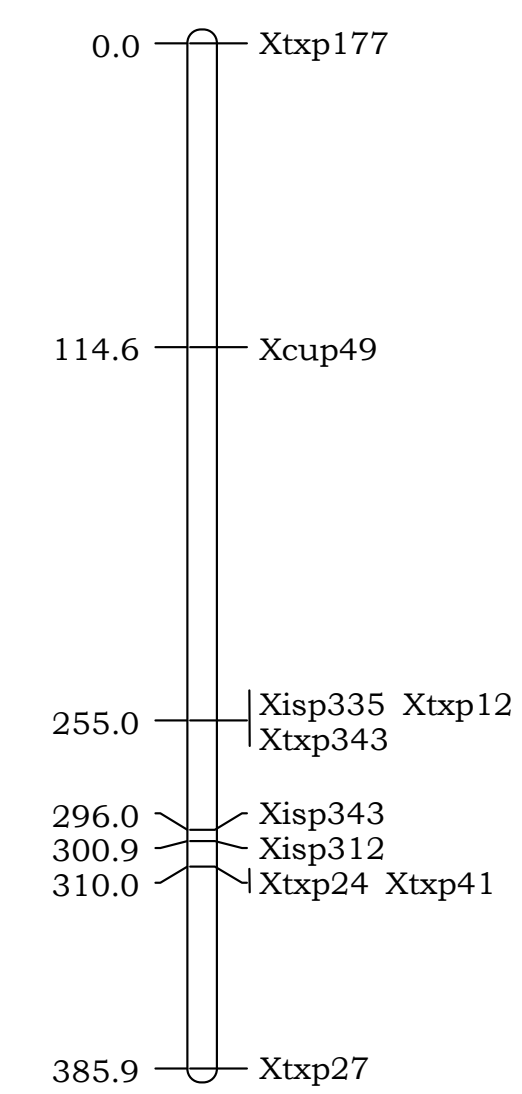


Figure.1 QTL position of sugar cane aphid resistance for 213 recombinant inbred population derived from cross $296 \mathrm{~B} \times$ IS 18551 across two screening environments at Patancheru, during 2002-2004.

$\mathbf{E}$

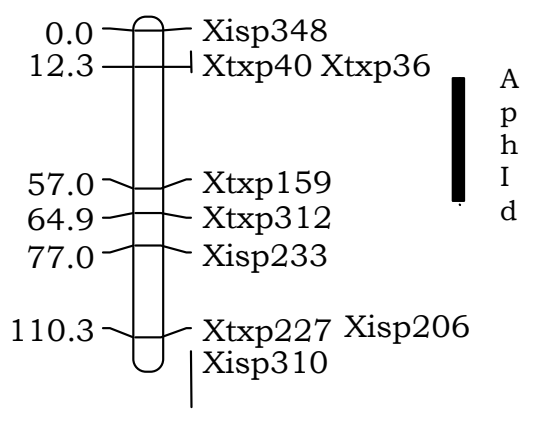

$\mathbf{F}$

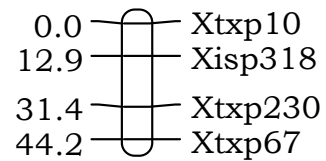

G

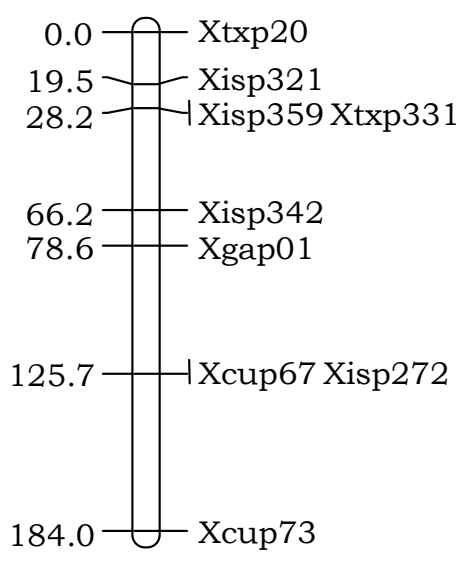

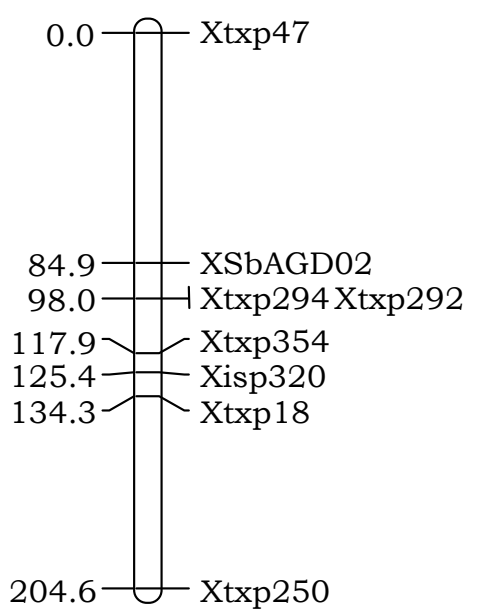

I

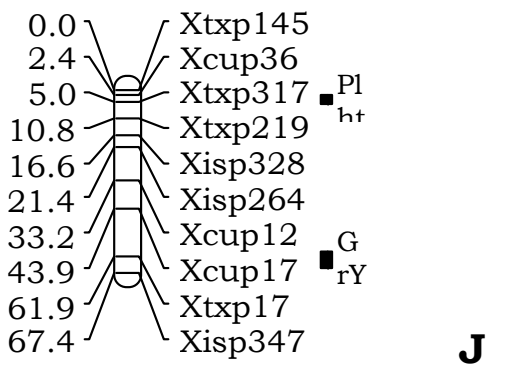

$\mathbf{H}$

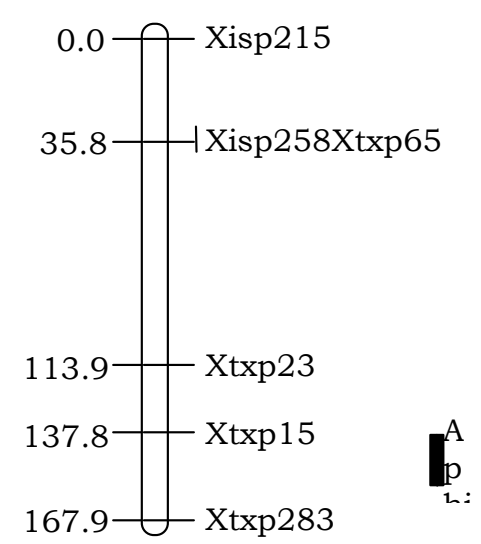


Figure.1 QTL positions of shoot fly resistance component traits for 213 recombinant inbred population derived from cross $296 \mathrm{~B} \times$ IS 18551 under two screening environments, late kharif (indicated by purple color) and rabi (indicated by pink color) at Patancheru during 2002-2004.

$\mathbf{A}$

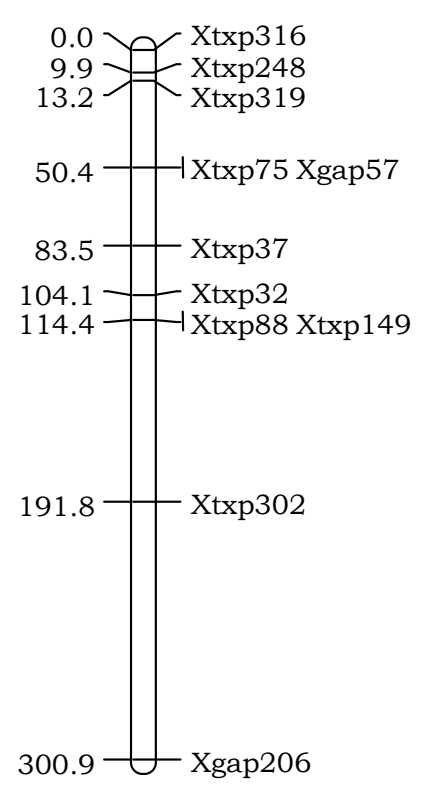

B

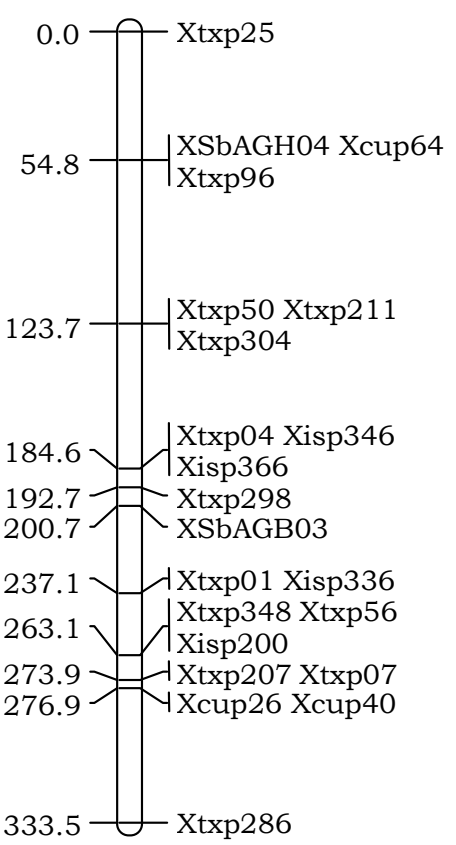

$\mathbf{C}$

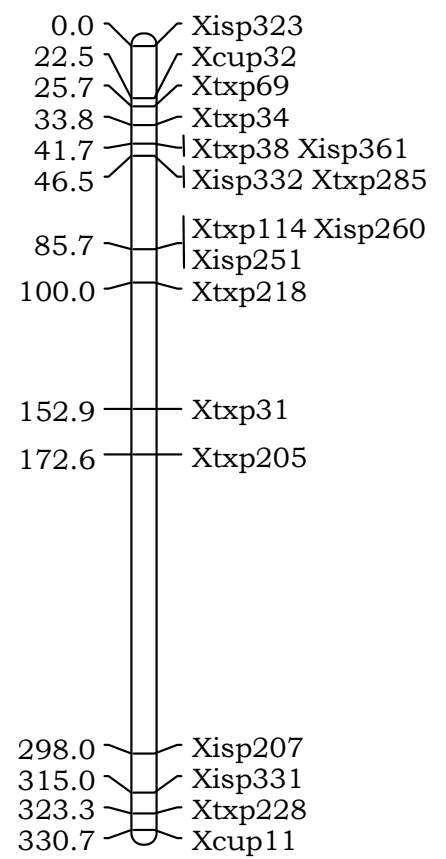

D-

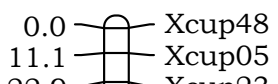

$22.9-$ Xcup23
D-

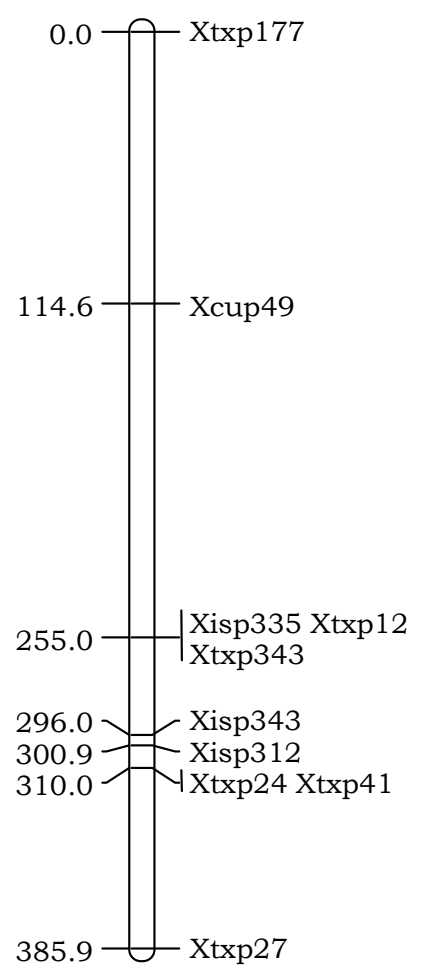


Figure.1 QTL positions of shoot fly resistance component traits for 213 recombinant inbred population derived from cross $296 \mathrm{~B} \times$ IS 18551 under two screening environments, late kharif (indicated by purple color) and rabi (indicated by pink color) at Patancheru during 2002-2004

$\mathbf{E}$

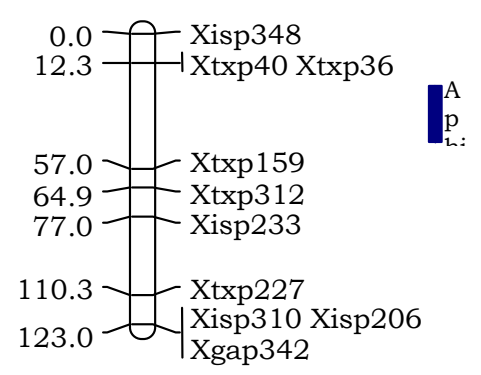

G

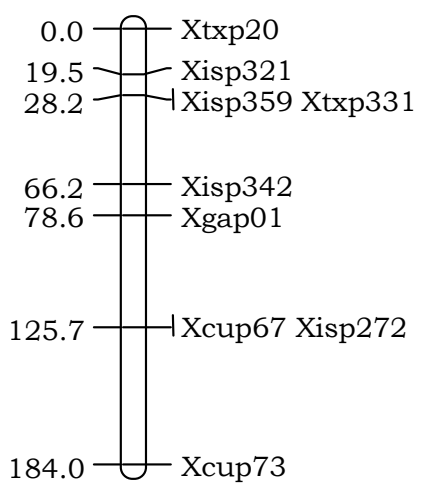

I

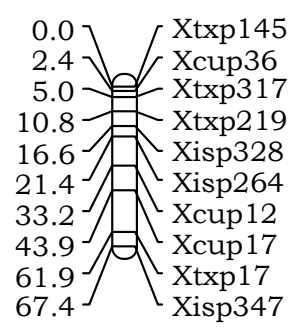

$\mathbf{H}$

$\mathbf{J}$

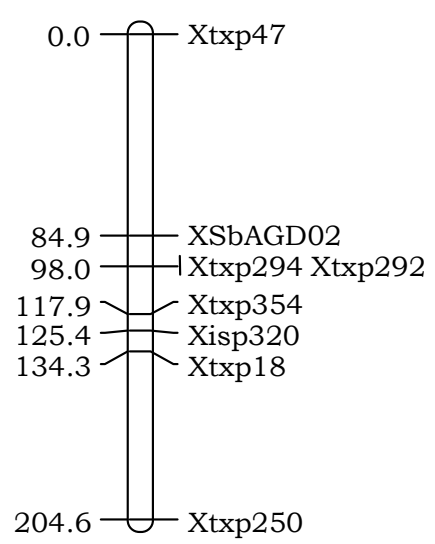

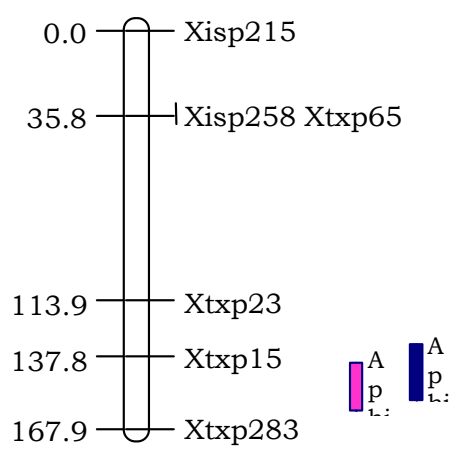


Final simultaneous fit analysis these two QTLs together explained only $18.6 \%$ of the adjusted phenotypic variance in polled RIL means with peak LOD value of $10.35 \%$. In across season QTL analysis, the QTL mapped on LG ' $\mathrm{J}$ ' was a major one; explaining $20.4 \%$ of the observed phenotypic variance with a peak LOD value 9.26. The QTL mapped on LG ' $E$ ' exhibited significant $Q \times$ E interaction while the QTL mapped on LG 'J' showed non-significance $\mathrm{Q}$ x $\mathrm{E}$ interaction. The favorable additive genetic effects for these two QTLs were contributed by alleles from aphid tolerant parent IS 18551.

\section{References}

Balikai, R.A., 2001. Bioecology and management of the sorghum aphid, Melanaphis sacchari. Ph.D. Thesis, University of Agricultural Sciences, Dharwad, Karnataka, India, 203pp.

Bhattramakki, D., J. Dong, A.K. Chhabra and G.E. Hart. 2000. An integrated SSR and RFLP linkage map of Sorghum bicolor (L.) Moench. Genome, 43: 988-1002.

FAOSTAT. 2004. http://apps.fao.org/default. htm

FAS. 2005. http://fas.usda.gov/ FAS Online. United States Department of Agriculture, Foreign Agricultural Service.

Haldane, J.B.S. 1919. The combination of linkage values and the calculation of distance between the loci of linked factors. J. Genet. 8: 299-309.

Haley, C.S. and S.A. Knott. 1992. A simple regression method for mapping quantitative trait loci in the line crosses using flanking markers. Heredity, 69: 315-324.

Hash, C.T. and P. Bramel-Cox. 2000. Survey of molecular marker applications. In Application of Molecular Markers in Plant Breeding. (Ed. Haussmann,
B.I.G., H.H. Geiger, D.E. Hess, C.T. Hash and P. Bramel-Cox). Training manual for seminar held at IITA, Ibadan, Nigeria, 16-17 August 1999. International Crops Research Institute for the Semi-Arid Tropics, Patancheru, India, pp. 3-12.

International Crops Research Institute for the Semi-Arid Tropics (ICRISAT). 1996. The world sorghum and millet economies: Facts, trends and outlook. Rome, Italy: Food and Agricultural Organization of the United Nations (FAO), and Patancheru, A.P. 502 324, India: International Crops Research Institute for the Semi-arid Tropics (ICRISAT). 72 pp.

Jansen, R.C. and P. Stam. 1994. Highresolution quantitative traits into multiple loci via interval mapping. Genetics, 136: 1447-1455.

Mote, U.N. 1983. Epidemics of delphacids and aphids on winter sorghum. Sorghum Newsl. 26, 76.

Mote, U. N., Kadam, J.R. 1984. Incidence of (Aphis sacchari Zehnt) in relation to sorghum plant characters. Sorghum Newsl. 27, 86.

Mote, U.N., J.R. Kadam and D.R. Bapat. 1985. Recovery resistance to shoot fly in some sorghum hybrids. J. Maharashtra Agric. Univ. 10: 190193.

Mote, U.N., Shinde, M.D., Bapat, D.R. 1985. Screening of sorghum collections for resistance to aphids and oily maLODy of winter sorghum. Sorghum Newsl. 28,13 .

Utz, H.F. and A.E. Melchinger. 2000. PLABQTL: A computer program to map QTL (version 1.1). Institute für Pflanzenzüchtung, Saatgutforschung und Populationsgenetik, Universitaet Hohenheim, D-70593 Stuttgart, Germany.

Waghmare, A.G., Varshneya, M.C., Khandge, 
S.V., Thakur, S.S., Jadhav, A.S., 1985. Effects of meteorological parameters on the incidence of aphids on sorghum. J. Mah. Agric. Univ. 20,
307-308.

Zeng, Z.B. 1994. Precision mapping of quantitative trait loci. Genetics, 136: 1457-1468.

\section{How to cite this article:}

Mehtre, S.P., C.T. Hash, H.C. Sharma, S.P. Deshpande and Narkhede, G.W. 2019. Mapping of Quantitative Trait Loci (QTLs) Associated with Sugarcane Aphids Resistance in Recombinant Inbreed Population of Sorghum [Sorghum bicolor (L.) Moench]. Int.J.Curr.Microbiol.App.Sci. 8(03): 2593-2602. doi: https://doi.org/10.20546/ijcmas.2019.803.307 